Research paper

\title{
Antibacterial potential of Urtica dioica and Lavandula angustifolia extracts against methicillin resistant Staphylococcus aureus isolated from diabetic foot ulcers
}

\author{
Soraia Zenão ${ }^{\mathrm{a}}$, Alfredo Aires ${ }^{\mathrm{b}}$, Carla Dias ${ }^{\mathrm{c}}$, Maria José Saavedra ${ }^{\mathrm{c}}$, Conceição Fernandes ${ }^{\mathrm{a}, *}$ \\ ${ }^{a}$ Mountain Research Center, CIMO, Escola Superior Agrária - Instituto Politécnico de Bragança, Campus de Santa Apolónia - Apartado 1172, $5301-855$ Bragança, \\ Portugal \\ ${ }^{\mathrm{b}}$ Centre for the Research and Technology for Agro-Environment and Biological Sciences, CITAB, Universidade de Trás-os-Montes e Alto Douro, UTAD, Quinta de Prados, \\ 5001-801 Vila Real, Portugal \\ ${ }^{c}$ Animal and Veterinary Research Centre, CECAV, Universidade de Trás-os-Montes e Alto Douro, UTAD, Quinta de Prados, 5001-801 Vila Real, Portugal
}

\section{A R T I C L E I N F O}

\section{Keywords:}

Antibacterial activity

Lavender

MRSA

Natural products

Nettle

Phytochemicals

\begin{abstract}
A B S T R A C T
Despite the antibacterial potential of plant extracts against several bacterial infections, until now, no major studies have been published about the effect of lavender and nettle leaves against methicillin-sensitive and methicillin-resistant strains of Staphylococcus aureus (MSSA and MRSA, respectively). Thus, the authors studied their antibacterial potential against MSSA and MRSA from diabetic foot ulcers in order to find alternatives to the systematic use of antibiotics. Phenolic acids, flavonoids, flavones and flavonols were extracted from lavender and nettle leaves and characterized by HPLC-DAD/Vis. Disc diffusion assay and minimum inhibitory concentration (MIC) were used to assess their antibacterial activity. A direct association between the high content of hydroxycinnamic acids (chlorogenic acid, caffeic acid, rosmarinic acid) and flavonoids (quercetin) and decreasing bacterial growth activity was noted. The fact that lavender and nettle are rich in hydroxycinnamic acids and quercetin seems to explain the high antibacterial potential of these plant and the differences between them.
\end{abstract}

\section{Introduction}

Diabetes mellitus is a disease with multifaceted complications and diabetic foot wounds, and subsequent foot ulceration, is one of the most common, with a prevalence that ranges from $4 \%$ to $10 \%$ (Singh et al., 2005). Diabetic foot ulcers frequently become infected and are a major cause of global hospital admissions and account for more than half of non-traumatic lower limb amputations (Dang and Boulton, 2003; Pinzur et al., 2005). It is well recognized that diabetic foot infection is polymicrobial, and Staphylococcus aureus is the pathogen most frequently isolated (Kim et al., 2012; Dunyach-Remy et al., 2016; Reveles et al., 2016). Due to the frequent use of antibiotics, S. aureus strains have evolved resistance against the most abundantly used therapeutics and the treatment of methicillin-resistant $S$. aureus (MRSA), infections is complicated by the fact that these strains are susceptible to only few antimicrobials (Kim et al., 2012). The World Health Organization, has developed a global priority list of antibioticresistant bacteria, to help in prioritizing the research and development of new and effective antibiotic treatments (World Health Organization,
2017); MRSA is classified as high priority. Also, epidemiological studies showed that MRSA, besides being multidrug resistant, has emerged as a serious and common problem in patients with diabetic foot ulcers (Kim et al., 2012), therefore, the research for alternative measures to antimicrobials is imperative. Recent strategies have been the research for natural compounds largely present in plants with recognized antimicrobial properties (González-Lamothe et al., 2009). Thousands of plant species have been tested for antimicrobial properties, but still the vast majority has not been adequately evaluated against MRSA, such as lavender (Lavandula angustifolia Mill) and nettle (Urtica dioica L). Lavender, a plant, from the lamiaceae family is recognized to act as an antioxidant and to be anti-inflammatory, as well as having antimicrobial effects (Moon et al., 2006; Field et al., 2008; Kritsidima et al., 2009; Dobesberger and Buchbauer, 2011). Similar reports have been made about nettle leaves, a perennial plant belonging to the urticacea family. Nettle extracts can have beneficial effects due to their levels of flavonoids, carotenoids, sterols and minerals (Aksu and Kaya, 2004; Sebranek et al., 2005; Karabacak and Bozkurt, 2008) and have shown antimicrobial activity against several microorganisms (Gülçin et al.,

\footnotetext{
* Corresponding author.

E-mail address: conceicao.fernandes@ipb.pt (C. Fernandes).
} 
2004; Tahri et al., 2000; Rieheman et al., 1999). Despite the beneficial properties of lavender and nettle, no studies have been conducted into their effects on MRSA, particularly against strains isolated from diabetic foot ulcers.

Therefore, the aim of this study was to evaluate the biological potential of nettle and lavender, as natural sources of bioactive compounds with antibacterial effect against methicillin-sensitive $S$. aureus (MSSA) and MRSA, isolated from diabetic foot ulcers. Results from this study could contribute to clarify whether these plants can be useful as alternatives or in combination with traditional antibiotic therapy.

\section{Material and methods}

\subsection{Plant material}

Lavender (Lavandula angustifolia Mill) and nettle (Urtica dioica $\mathrm{L}$ ) were collected in a field located in Northern Portugal ( $460 \mathrm{~m}, 41^{\circ} 17^{\prime} \mathrm{N}$ and $7^{\circ} 44^{\prime} \mathrm{W}$ ) in spring and identified by Dr. A. Aires, University of Trásos-Montes and Alto Douro (UTAD), Portugal. Field collection standards were also stored in the botanical collection of the Department of Botany (UTAD). Plants leaves were freeze-dried (Ultra-dry Sytems, FTSsystem $^{\mathrm{TM}}$ ) and powdered prior to be used in experimental work.

\subsection{Extraction}

The powder was extracted in triplicate with ethanol $70 \%$, in a water bath $\left(70^{\circ} \mathrm{C}, 1 \mathrm{~h}\right)$. Extracts were then centrifuged at $1500 \mathrm{rpm}(5 \mathrm{~min}$ $4{ }^{\circ} \mathrm{C}$ ), filtered and $1 \mathrm{~mL}$ aliquots of each extract were collected and filtered again (Spartan $\emptyset 0.13 \mathrm{~mm}$ ) before being placed in HPLC vials and stored at $20^{\circ} \mathrm{C}$ until analysis. Remaining hydro-alcoholic extracts were dried in the rotary evaporator at $40{ }^{\circ} \mathrm{C}$ until complete dehydration. Residues were stored at $-20^{\circ} \mathrm{C}$ for antibacterial experimental assay.

\subsection{Total phenolic and flavonoid content}

Total phenolic content (TPC) and total flavonoid content (TFC) were determined colorimetrically using a 96-well microplate (Costar, Corning, New York, USA). The TPC was measured based on the Folin-Ciocalteau assay (Singleton et al., 2002), with some modifications. Briefly, $20 \mu \mathrm{L}$ of plant extract was added to each microplate well.

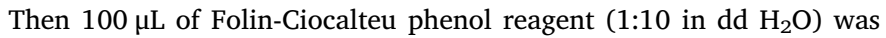
added, followed by addition of $80 \mu \mathrm{L}$ of $7.5 \% \mathrm{Na}_{2} \mathrm{CO}_{3}$. Microplates were incubated for $15 \mathrm{~min}$ at $45^{\circ} \mathrm{C}$ (warm-bath) and absorbance was read at $765 \mathrm{~nm}$ against a blank (solvent extraction) in a microplate reader (Multiskan $^{\mathrm{TM}}$, FC Microplate Photometer, Thermo Scientific). A calibration curve, using gallic acid, was used for quantifications. Values were expressed as $\mathrm{mg}$ gallic acid equivalent (GAE) $\mathrm{g}^{-1}$ dry weight (mg GAE $\mathrm{g}^{-1} \mathrm{~d} \mathrm{w}$ )

The TFC in samples was measured based on $\mathrm{AlCl}_{3}$ spectrophotometer method (Shin et al., 2008) with some modifications. To each microplate well, $100 \mu \mathrm{L}$ of ultra-pure water was added, followed by $10 \mu \mathrm{L}$ of $\mathrm{NaNO}_{2}$ and $25 \mu \mathrm{L}$ of each plant extract. The mixture was left to stand in the dark at room temperature for $5 \mathrm{~min}$. Then, $15 \mu \mathrm{L}$ of $\mathrm{AlCl}_{3}$ $10 \%$ was added and left to stand in the dark at room temperature for

6 min. After, $100 \mu \mathrm{L}$ of $\mathrm{NaOH} 1 \mathrm{M}$ and $50 \mu \mathrm{L}$ of ultra-pure water were added to each well. Absorbance was measured at $510 \mathrm{~nm}$ in microplate reader, against blank. A calibration curve, using catechin, was used for quantifications. Values were expressed as $\mathrm{mg}$ catechin equivalent (CAE) $\mathrm{g}^{-1}$ dry weight $\left(\mathrm{mg} \mathrm{CAE} \mathrm{g}^{-1} \mathrm{~d} \mathrm{w}\right.$ ). The mean and standard deviation within samples were calculated for all cases.

\subsection{Phytochemical composition}

Phytochemical composition was evaluated by HPLC-diode array detector (DAD)/Vis system. In order to increase chromatogram accuracy, $\mathrm{HCl}(2 \mathrm{M})$ in $50 \%$ methanol and tertiary butylhydroquinone (TBHQ) were added to $200 \mu \mathrm{L}$ of each plant extract and placed in the heater at $80^{\circ} \mathrm{C}$ for $2 \mathrm{~h}$ and then centrifuged (model 2-16 K, Sigma, Osterode, Germany) at $13000 \mathrm{rpm}$ for $20 \mathrm{~min}$. Supernatant was collected and injected in HPLC. The eluent was constituted by water with $1 \%$ of trichloroacetic acid (TFA) (solvent A) and acetonitrile with $1 \%$ TFA (solvent B). Chromatograms were recorded at 280, 320, and $370 \mathrm{~nm}$ with a C18 column. Phytochemical identification was carried out using peak retention time and UV spectra. The quantification was carried out using external calibration curves with commercial phenolic standards (Extrasynthese, Cedex, France).

\subsection{Bacteria strains}

Samples were taken from diabetic foot infections at Hospital Centre of Trás-os-Montes e Alto Douro, Vila Real, Portugal (under a protocol with UTAD university). Isolates were identified by morphological and biochemical tests, followed by Kirby-Bauer antibiotic sensitivity assays. Different antibiotics such as Oxacillin, Levofloxacin and Vancomycin $(10 \mu \mathrm{g})$ were used. Ten isolates of MSSA and ten isolates of MRSA were used in this study.

\subsection{Antibacterial activity of plants extracts}

Stored plant extracts were diluted with 10\% dimethylsulfoxide (DMSO) (Sigma-Aldrich, Germany) to a concentration of $100 \mathrm{mg} \mathrm{mL}^{-1}$ to be used in disc diffusion and minimum inhibitory concentration (MIC) assays.

Disc diffusion assay (Jorgensen and Turnidge, 2007) was used to screen the antibacterial effect of plant extracts. Test isolates were grown on nutrient agar plates and later inoculated on nutrient broth to log phase. Test bacterial suspensions turbidity was adjusted to 0.5 MacFarland units. Petri dishes were prepared with $20 \mathrm{~mL}$ of Mueller-Hinton Agar (Oxoid, UK) and seeded with bacterial suspensions. Sterile paper discs were impregnated with $15 \mu \mathrm{L}$ of each previous extract solution in DMSO (corresponding to a $1.5 \mathrm{mg}$ of extract) and placed on an agar plate. Incubation was at $37^{\circ} \mathrm{C}$ for $24 \mathrm{~h}$. Discs of gentamicin (CN10 Oxoid CT0024B, UK) were used as positive control and discs impregnated with DMSO were used as negative control. After incubation, the diameter (mm) of the inhibitory zone around the disc was recorded. All the tests were performed in triplicate and the antibacterial activity was expressed as the mean of inhibition diameters $(\mathrm{mm})$ produced $\pm \mathrm{SD}$ (standard deviation).

Antibacterial activity index (Aai) was used for efficiency comparison between plant extracts and positive control (antibiotic), using the following formula: Aai $=\left(A_{1}-A_{0}\right) / A_{1}$, where $A_{1}$ is diameter of inhibition zone of compound tested, $A_{0}$ is the diameter of sterile paper disc. The rate values below 0.14 (representing the boundary near the halo limit) were considered insignificant and thus ignored when specifying MIC.

Minimum inhibitory concentration (MIC) was evaluated by a resazurin microdilution assay (Sarker et al., 2007). Bacteria tested were picked from overnight cultures in brain heart agar (Oxoid, UK). A small portion of bacteria was transferred into a bottle with $50 \mathrm{~mL}$ of Mueller-Hinton broth (Oxoid, UK), capped and placed in an incubator overnight at $37^{\circ} \mathrm{C}$. After $16 \mathrm{~h}$ of incubation, bacterial suspension was adjusted to an optical density of 0.5 measured at OD500 $\mathrm{nm}$. The resazurin solution (Sigma-Aldrich, Germany) was prepared as $3.4 \mathrm{mg} \mathrm{mL}^{-1}$ in sterile distilled water. A 96-wells sterilized microplate was used. A volume of $100 \mu \mathrm{L}$ of Mueller-Hinton broth was used in each well together with $100 \mu \mathrm{L}$ of extract solution, or positive control. From the first well (belonging to the first horizontal line) $100 \mu \mathrm{L}$ was taken and added to the next well and then this step was repeated to each of the following wells in the vertical line, allowing a serial fold dilution of decreasing concentration (range of $50 \mathrm{mg} / \mathrm{mL}$ to $0.024 \mathrm{mg} / \mathrm{mL}$ ). In 
Table 1

Quantitative phenolic and flavonoid compounds ${ }^{\mathrm{a}}$ in nettle and lavender extracts.

\begin{tabular}{lll}
\hline Plant extracts & Compound & Average level \\
\hline $\begin{array}{l}\text { Nettle } \\
\left(\mu \mathrm{g} \mathrm{g}^{-1} \mathrm{~d} \mathrm{w}\right)\end{array}$ & Protocatechuic acid & $5.90 \pm 0.90$ \\
& Chlorogenic acid & $71.49 \pm 1.70$ \\
& Caffeic acid & $163.01 \pm 3.63$ \\
& Rutin & $106.01 \pm 2.50$ \\
& Isoquercetin & $30.2 \pm 0.56$ \\
& Quercetin & $35.67 \pm 0.80$ \\
& p-Coumaric acid & $10.55 \pm 0.82$ \\
& Total phenolics (mg GAE g $\left.{ }^{-1} \mathrm{dw}\right)$ & $25.85 \pm 1.2$ \\
Lavender & Total flavonoids (mg CAE g $\left.{ }^{-1} \mathrm{dw}\right)$ & $22.47 \pm 0.7$ \\
$\left(\mu \mathrm{g} \mathrm{g}{ }^{-1} \mathrm{~d} w\right)$ & $9.09 \pm 0.54$ \\
& p-Hydroxibenzoic acid & $61.42 \pm 2.00$ \\
& Caffeic acid & $36.18 \pm 0.89$ \\
& Apigenin derivatives & $46.95 \pm 1.27$ \\
& Syringic acid & $189.25 \pm 3.99$ \\
& Ferulic acid & $12.71 \pm 0.33$ \\
& Rutin & $11.97 \pm 0.37$ \\
& Apigenin-7-O-glucoside & $10.69 \pm 0.52$ \\
& Luteolin-7-O-glucoside & $183.99 \pm 4.48$ \\
& Rosmarinic acid & $2.98 \pm 0.16$ \\
& Quercetin & $1.87 \pm 0.06$ \\
& Kaempferol & $0.58 \pm 0.05$ \\
& Isorhamnetin & $34.54 \pm 0.2$ \\
& Total phenolics (mg GAE g $\left.{ }^{-1} \mathrm{dw}\right)$ & $14.25 \pm 0.6$ \\
& Total flavonoids (mg CAE g ${ }^{-1} \mathrm{dw}$ ) & \\
& &
\end{tabular}

${ }^{\text {a }}$ Results are expressed as mean \pm SD (standard deviation) of 3 replicates.

addition, $20 \mu \mathrm{L}$ of bacterial suspension and $20 \mu \mathrm{L}$ of resazurin solution was added to each well. Microplates were incubated at $37^{\circ} \mathrm{C}$ for $18-24 \mathrm{~h}$. All tests were performed in triplicate and MIC was then assessed visually by the color change of resazurin in each well (blue to pink in the presence of bacteria growth). After each MIC identification, the content of the MIC well was added to Mueller-Hinton Agar plates and incubated at $37^{\circ} \mathrm{C}$ overnight to evaluate bacterial effect of extracts: bactericidal when no visible growth was observed and bacteriostatic when formation of colonies occurred.

\subsection{Data analysis}

The data were analyzed using the statistical program SPSS version 17.0 (Statistical Package for the Social Sciences). Data was compared applying nonparametric Wilcoxon test $(p<0.05)$.

\section{Results and discussion}

Table 1 shows the phenolics (TPC) and flavonoids (TFC) quantified in lavender and nettle leaf extracts. Generally, for nettle TPC was higher than TFC, and among phenolic acids, caffeic acid was the most representative and protocatechuic acid and p-coumaric acid were found at moderate levels. A high content of flavonoids, such as rutin, isoquercetin and quercetin, was also found. Lavender samples had the hydroxycinnamic and hydroxybenzoic acids, such as caffeic, ferulic, syringic and rosmarinic acids, all non-flavonoids, as the most representative.

Generally, lavender had a higher quantity and diversity of phenolic compounds, and lower levels of flavonoids, than nettle leaves, which can be important to endorse the type of biological activity of each extract. It is well accepted that higher content of hydroxycinamic acids, such as chlorogenic and caffeic acids, as well as flavonoids, such as quercetin and quercetin-related compounds, are important since they are highly correlated with antioxidant, anti-inflammatory, antimicrobial and anticancer activities. In fact, quercetin has been reported as having antibacterial activity against $S$. aureus and Pseudomonas aeruginosa (Woènicka et al., 2013). Chlorogenic and caffeic acids are also reported to be important antimicrobial and antioxidant agents (Sung and Lee, 2010). Rosmarinic acid is a caffeic acid ester found in a variety of plants of the lamiaceae family such as lavender (as we observed in this work), and has been reported to be one compound with antioxidative, anti-inflammatory and anti-tumour effects (Zhang et al., 2010). Therefore, based on their composition, nettle and lavender may have significant potential, not only as a source of phytochemicals for the human diet, but more importantly, as a source of natural compounds with antimicrobial, anti-oxidative and anti-inflammatory activity.

The antibacterial activity of plant extracts was evaluated by the presence of an inhibition zone and results showed that lavender and nettle are effective against MSSA and MRSA (Table 2). The bacterial inhibition halos varied between $11.3-19.3 \mathrm{~mm}$ for nettle, and from 8.7-21.3 mm for lavender, although effectiveness was not significantly different between extracts. For gentamicin (positive control), inhibition halos varied between 17.7 and $24.7 \mathrm{~mm}$, showing effectiveness that was

Table 2

In vitro antimicrobial activity of positive control and extracts of nettle and lavender, determined by the diameter of inhibition zones (mm).

\begin{tabular}{|c|c|c|c|}
\hline Bacterial isolates & Positive control (gentamicin) & Nettle extracts & Lavender extracts \\
\hline MJMC 001 (MSSA) & $17.7 \pm 0.6$ & $11.3 \pm 0.6$ & $8.7 \pm 0.6$ \\
\hline MJMC 002 (MSSA) & $19.7 \pm 0.6$ & $17.3 \pm 0.6$ & $21.3 \pm 0.6$ \\
\hline MJMC 003 (MRSA) & $24.7 \pm 1.5$ & $19.3 \pm 2.5$ & $20.3 \pm 1.2$ \\
\hline MJMC 004 (MSSA) & $20.7 \pm 1.2$ & $15.7 \pm 1.2$ & $20.7 \pm 1.5$ \\
\hline MJMC 007 (MSSA) & $22.3 \pm 1.2$ & $18.3 \pm 1.5$ & $15.7 \pm 1.5$ \\
\hline MJMC 008 (MSSA) & $20.3 \pm 1.5$ & $15.3 \pm 2.1$ & $13.0 \pm 1.7$ \\
\hline MJMC 009 (MRSA) & $22.7 \pm 1.5$ & $19.3 \pm 2.1$ & $21.3 \pm 0.6$ \\
\hline MJMC 010 (MRSA) & $20.0 \pm 1.0$ & $16.7 \pm 0.6$ & $16.0 \pm 1.0$ \\
\hline MJMC 011 (MRSA) & $20.7 \pm 1.5$ & $18.0 \pm 1.0$ & $20.3 \pm 2.5$ \\
\hline MJMC 014 (MRSA) & $21.0 \pm 2.7$ & $16.3 \pm 2.1$ & $14.0 \pm 2.0$ \\
\hline MJMC 016 (MSSA) & $20.7 \pm 2.3$ & $16.7 \pm 1.5$ & $17.0 \pm 1.0$ \\
\hline MJMC 018 (MSSA) & $20.7 \pm 2.5$ & $17.7 \pm 0.6$ & $16.3 \pm 1.5$ \\
\hline MJMC 020 (MRSA) & $21.3 \pm 1.5$ & $17.3 \pm 0.6$ & $16.7 \pm 1.2$ \\
\hline MJMC 021 (MSSA) & $23.0 \pm 0.0$ & $17.3 \pm 0.6$ & $17.0 \pm 1.0$ \\
\hline MJMC 022 (MRSA) & $21.3 \pm 1.5$ & $16.7 \pm 0.6$ & $16.0 \pm 1.0$ \\
\hline MJMC 024 (MSSA) & $20.3 \pm 1.2$ & $17.0 \pm 0.0$ & $15.0 \pm 1.0$ \\
\hline MJMC 025 (MRSA) & $19.3 \pm 1.5$ & $17.7 \pm 0.6$ & $17.0 \pm 1.0$ \\
\hline MJMC 026 (MSSA) & $19.7 \pm 1.5$ & $18.3 \pm 0.6$ & $16.7 \pm 0.6$ \\
\hline MJMC 027 (MRSA) & $21.0 \pm 1.0$ & $18.3 \pm 1.5$ & $17.3 \pm 1.5$ \\
\hline MJMC 029 (MRSA) & $19.3 \pm 0.6$ & $16.0 \pm 1.0$ & $16.7 \pm 1.5$ \\
\hline Result means (MSSA) ${ }^{\mathrm{b}}$ & $20.51 \pm 1.45$ & $16.49 \pm 2.07$ & $16.14 \pm 3.59$ \\
\hline Result means (MRSA) ${ }^{\mathrm{b}}$ & $21.13 \pm 1.61$ & $17.56 \pm 1.17$ & $17.56 \pm 2.32$ \\
\hline
\end{tabular}

${ }^{\text {a }}$ Results are expressed as mean \pm SD (standard deviation) of 3 replicates.

${ }^{\mathrm{b}}$ Results are expressed as mean $\pm \mathrm{SD}$ (standard deviation) of 10 strains tested. 
A

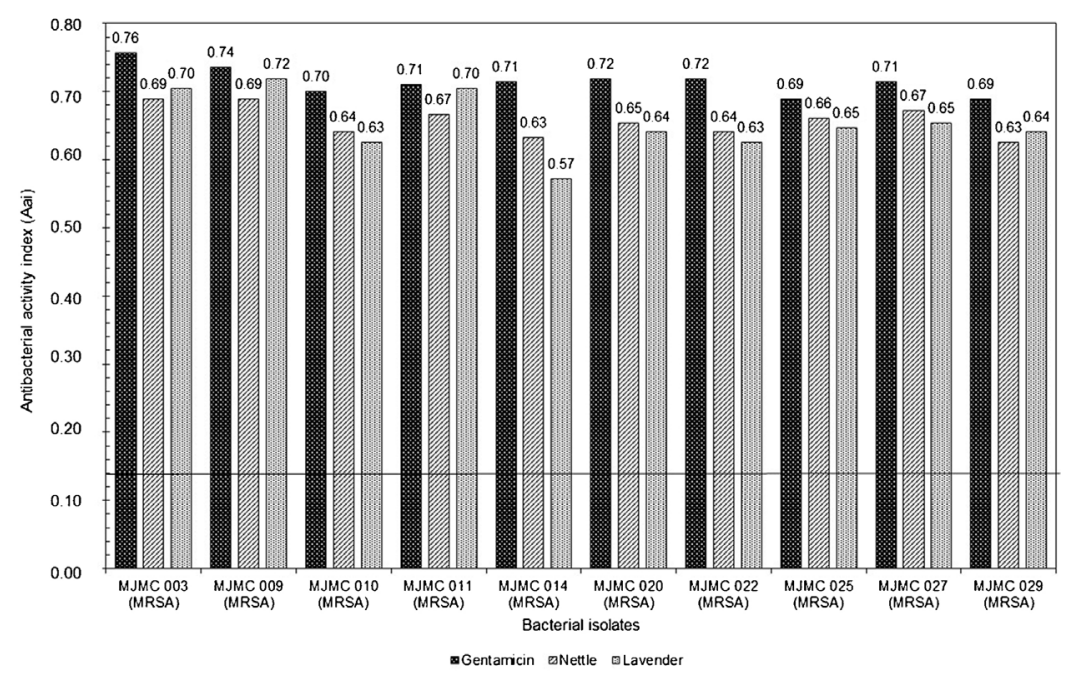

B

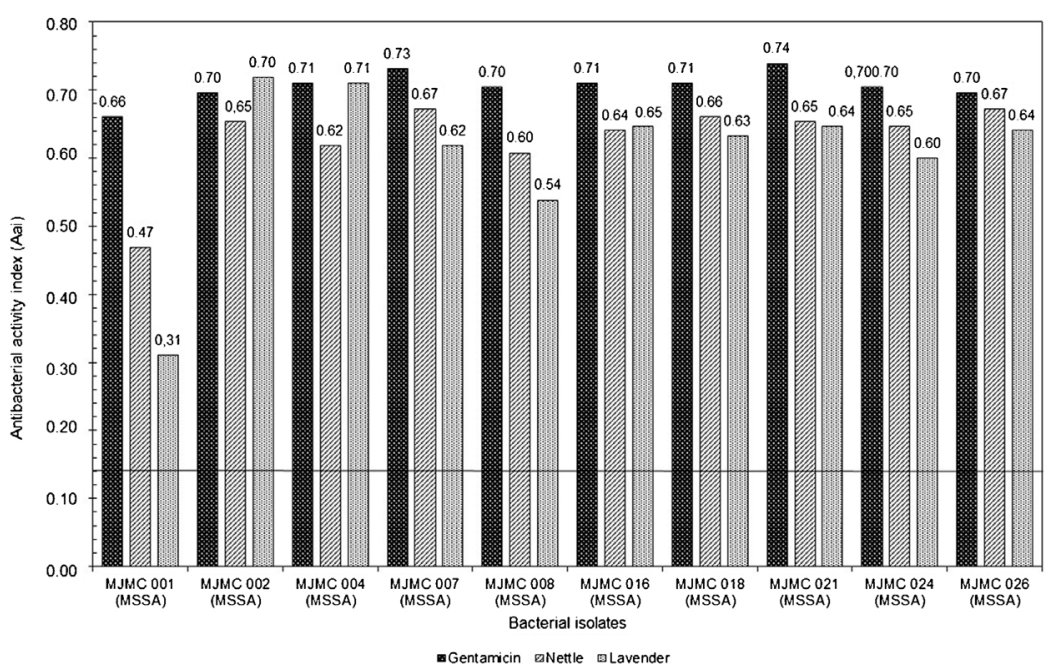

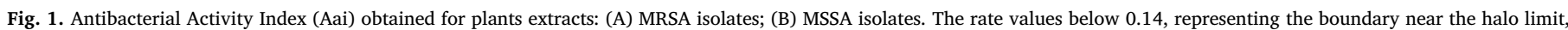
were considered insignificant.

significantly different from the extracts. However, considering MRSA mean values, the relative difference between antibiotic and plants extracts does not exceed $17 \%$. This similarity between antibiotic and both, lavender and nettle extracts, reveals that these plants can be a source of phytochemicals with antimicrobial activity, as shown by antibacterial activity index (Aai) (Fig. 1A and B). The Aai was used for efficiency comparison between plant extracts and antibiotics, and values obtained were quite similar, reinforcing this idea. Except for one MSSA isolate (MJMC 001), the average difference of Aai between gentamicin and nettle was $8.1 \%$ and $9 \%$ for MRSA and MSSA isolates, respectively, whilst between gentamicin and lavender was $8.6 \%$ and $10.1 \%$ for MRSA and MSSA, respectively. These results mean that nettle and lavender, at the tested concentrations, show an interesting antimicrobial activity, compared with the antibiotic gentamicin.

Results from MIC assay also showed parallelism between these plant extracts (Table 3). It was noted that for nettle extracts MIC values ranged between $0.0625-0.500 \mathrm{mgmL}^{-1}$ and for lavender extracts ranged between $0.0625-1.0 \mathrm{mg} \mathrm{mL}^{-1}$, closer to the MIC values of the positive control gentamicin, which were lower than $0.039 \mathrm{mg} \mathrm{mL}^{-1}$. In addition, the main bacterial effect observed was bacteriostatic, for both lavender and nettle extracts. It seems that these extracts, rather than eliminate, limit exponential bacterial growth, which is also important from a pharmaceutical point of view.

Based on HPLC results, it seems that the high content of identified phenolics, such as chlorogenic acid, caffeic acid, rosmarinic acid and rutin in nettle and lavender extracts, could be the main reason for the antibacterial capacity of these extracts against $S$. aureus isolates. Recent experiments with pure phenolic compounds (Cueva et al., 2010, 2012) showed that phenolic acids, such as caffeic acids, were very effective against both gram negative and gram positive bacteria. Thus, plant extracts with a higher content of caffeic acid, as we have observed, could increase efficiency in bacteria growth inhibition. In fact, nettle extracts present an average $163 \mu \mathrm{g} \mathrm{g}^{-1}$ dry weight; whereas lavender extracts present $61 \mu \mathrm{g} \mathrm{g}^{-1}$ dry weight of caffeic acid. RodríguezVaquero et al. (2007) also found that caffeic acid inhibited the growth of $P$. aeruginosa and $S$. aureus which is in agreement with our results for $S$. aureus isolates. Furthermore, previous studies reported that other phenolics, like ferulic acid, rosmarinic acid, rutin and quercetin, can be effective against other gram positive bacteria like Listeria monocytogenes (Liu, 2003; Saavedra et al., 2010). Antibacterial effects of these plant extracts were also observed in different situations (Akbari et al., 2015; Sasaki et al., 2015; Motamedi et al., 2014; Shahin et al., 2014).

However, previous researchers have stated that pure phenolic compounds are sometimes ineffective or less effective than phenolic 
Table 3

Minimum Inhibitory Concentration (MIC) and bacterial activity effects for nettle and lavender extracts. ${ }^{a}$

\begin{tabular}{|c|c|c|c|c|}
\hline \multirow[t]{2}{*}{ Bacterial isolates } & \multicolumn{2}{|l|}{ Nettle } & \multicolumn{2}{|l|}{ Lavender } \\
\hline & $\begin{array}{l}\text { MIC } \\
\left(\mathrm{mg} \mathrm{mL}^{-1}\right)\end{array}$ & Bacterial activity & $\begin{array}{l}\text { MIC } \\
\left(\mathrm{mg} \mathrm{mL}^{-1}\right)\end{array}$ & Bacterial activity \\
\hline MJMC 001 (MSSA) & $0.500 \pm 0.000$ & \multirow[t]{2}{*}{ Bacteriostatic } & $1.000 \pm 0.000$ & \multirow[t]{2}{*}{ Bacteriostatic } \\
\hline MJMC 002 (MSSA) & $0.250 \pm 0.000$ & & $0.250 \pm 0.000$ & \\
\hline MJMC 003 (MRSA) & $0.250 \pm 0.000$ & Bactericidal & $0.250 \pm 0.000$ & Bactericidal \\
\hline MJMC 004 (MSSA) & $0.188 \pm 0.088$ & \multirow[t]{15}{*}{ Bacteriostatic } & $0.063 \pm 0.000$ & \multirow[t]{17}{*}{ Bacteriostatic } \\
\hline MJMC 007 (MSSA) & $0.188 \pm 0.088$ & & $0.125 \pm 0.000$ & \\
\hline MJMC 008 (MSSA) & $0.500 \pm 0.000$ & & $0.250 \pm 0.000$ & \\
\hline MJMC 009 (MRSA) & $0.063 \pm 0.000$ & & $0.125 \pm 0.000$ & \\
\hline MJMC 010 (MRSA) & $0.125 \pm 0.000$ & & $0.250 \pm 0.000$ & \\
\hline MJMC 011 (MRSA) & $0.125 \pm 0.000$ & & $0.250 \pm 0.000$ & \\
\hline MJMC 014 (MRSA) & $0.125 \pm 0.000$ & & $0.250 \pm 0.000$ & \\
\hline MJMC 016 (MSSA) & $0.250 \pm 0.000$ & & $0.125 \pm 0.000$ & \\
\hline MJMC 018 (MSSA) & $0.250 \pm 0.000$ & & $0.500 \pm 0.000$ & \\
\hline MJMC 020 (MRSA) & $0.125 \pm 0.000$ & & $0.250 \pm 0.000$ & \\
\hline MJMC 021 (MSSA) & $0.188 \pm 0.088$ & & $0.188 \pm 0.088$ & \\
\hline MJMC 022 (MRSA) & $0.500 \pm 0.000$ & & $0.250 \pm 0.000$ & \\
\hline MJMC 024 (MSSA) & $0.375 \pm 0.177$ & & $0.125 \pm 0.000$ & \\
\hline MJMC 025 (MRSA) & $0.250 \pm 0.000$ & & $0.250 \pm 0.000$ & \\
\hline MJMC 026 (MSSA) & $0.250 \pm 0.000$ & & $0.250 \pm 0.000$ & \\
\hline MJMC 027 (MRSA) & $0.250 \pm 0.000$ & \multirow[t]{2}{*}{ Bactericidal } & $0.125 \pm 0.000$ & \\
\hline MJMC 029 (MRSA) & $0.250 \pm 0.000$ & & $0.250 \pm 0.000$ & \\
\hline
\end{tabular}

${ }^{\text {a }}$ Results are expressed as mean \pm SEM (standard error of the mean) of 3 replicates.

plant extracts, probably because of the additive/synergistic effects of the extracts. Additive and synergistic effects of phytochemicals in plants are responsible for their potent bioactive properties and the benefit of them is attributed to the complex mixture of phytochemicals present in the whole plants (Lowy, 2003). This seems to be the case here, since nettle and lavender presented similar antibacterial activity, despite the differences in average content of each phenolic identified in both extracts.

It is interesting to note that both MRSA and MSSA showed susceptibility towards the extracts tested. MRSA is resistant to all $\beta$ lactam antibiotics and this ability is due to the acquisition of the mecA gene (Lowy, 2003). This gene encodes PBP2a protein and when it is challenged by $\beta$-lactams, MRSA will use transpeptidase functionality of PBP2a to synthesize the cell wall (Wilke et al., 2005). However, specific compounds can affect this ability, causing cell wall disruption. Shintani et al. (2000) found that in presence of licoricidin and triazine dye, MRSA PBP2a synthesis during bacteria multiplication was affected. Also, the phenolics epicatechin gallate and epigallocatechin gallate have the ability to inhibit growth of MRSA by interference with PBP2a synthesis (Hamilton-Miller and Shah, 1999). No major studies have been published about the effect of nettle and lavender extracts against MRSA, but phenolics present in both could play a similar role.

Also, the structure of phenolic compounds, such as hydroxybenzoic and hydroxycinamic acid derivatives, could contribute to the activity observed against MRSA and MSSA. In fact, the presence of carboxylic acid $(\mathrm{COOH})$, two hydroxyl $(\mathrm{OH})$ groups in the para and ortho positions of the benzene ring and also a methoxyl (OCH3) group in the meta position are important for anti-microbial activity (Alves et al., 2013).

Though Staphylococcus aureus causes a wide swath of human diseases, including skin and soft tissue infections (Kim et al., 2012), a screen of the antibacterial effect of phenolics, identified in nettle and lavender extracts, was made on isolates of MSSA and MRSA, from diabetic foot ulcers. The antibacterial effects observed are noteworthy since it is well recognized that high levels of bacteria can delay or event prevent wound healing and impede surgical closure of diabetic ulcers, which may ultimately lead to amputation. Although phenolic compounds could be a solution for multi-resistance problems, their mechanism of action needs to be better understood and further clarified.

\section{Conclusions}

Our results highlight the antibacterial activity of nettle and lavender extracts against MRSA and MSSA. Based on this, we can conclude that these extracts can be used alone or in combination with antibiotics to limit the infections of these bacteria, or to prevent secondary opportunistic infectious agents. They can easily be used prophylactically in pharmaceutical formulations for topical applications, preventing the appearance of infections. In addition, they can be used in combination with lower doses of traditional antibiotics, reducing the time and severity of infections and occurrence of any possible antibiotic resistance, particularly in patients with diabetic foot ulcers.

\section{Conflict of interest}

The authors have declared that there is no conflict of interest.

\section{Acknowledgments}

The authors acknowledge the financial support provided by the FCT-Portuguese Foundation for Science and Technology (Carla DiasSFRH/BD/90120/2012 and Alfredo Aires-SFRH/BPD/65029/2009), under the Project PEst-OE/AGR/UI4033/2014.

\section{References}

Akbari, H., Fatemi, M.J., Iranpour, M., Khodarahmi, A., Baghaee, M., Pedram, M.S. Saleh, S., Araghi, S., 2015. The healing effect of nettle extract on second degree burn wounds. World J. Plast. Surg. 4 (1), 23-28.

Aksu, M.I., Kaya, M., 2004. Effect of usage Urtica dioica L on microbial properties of sucuk a Turkish dry-fermented sausage. Food Control 15, 591-595.

Alves, M.J., Ferreira, I.C.F.R., Froufe, H.J.C., Abreu, R.M.V., Martins, A., Pintado, M., 2013. Antimicrobial activity of phenolic compounds identified in wild mushrooms, SAR analysis and docking studies. J. Appl. Microbiol. 115, 346-357.

Cueva, C., Moreno-Arribas, M.V., Requena, T., Rodríguez, J.M., Vicente, F., Basilio, A., Bills, G.F., Martín-Álvarez, P.J., 2010. Antimicrobial activity of phenolic acids against commensal, probiotic and pathogenic bacteria. Res. Microbiol. 161, 372-382.

Cueva, C., Mingo, S., Muñoz-González, I., Bustos, I., Requena, T., del Campo, R., MartínÁlvarez, P.J., Bartolomé, B., Moreno-Arribas, M.V., 2012. Antibacterial activity of wine phenolic compounds and oenological extracts against potential respiratory pathogens. Lett. Appl. Microbiol. 54, 557-563.

Dang, C.N., Boulton, A.J., 2003. Changing perspectives in diabetic foot ulcer management. Int. J. Lower Extrem. Wounds 2, 4-12.

Dunyach-Remy, C., Ngba Essebe, C., Sotto, A., Lavigne, J.P., 2016. Staphylococcus aureus 
toxins and diabetic foot ulcers: role in pathogenesis and interest in diagnosis. Toxins 8 (7), 209.

Field, T., Cullen, C., Largie, S., Diego, M., Schanberg, S., Kuhn, C., 2008. Lavander bath oil reduces stress and crying and enhances sleep in very young infants. Early Hum. Dev. 84, 399-401.

Gülçin, I., Küfrevioğlu, O.I., Oktay, M., Büyükokuroğluc, M.E., 2004. Antioxidant, antimicrobial, antiulcer and analgesic activities of nettle (Urtica dioica L). J. Ethnopharmacol. 90, 205-215.

González-Lamothe, R., Gattuso, M.G., Diarra, M.S., Malouin, F., Bouarab, K., 2009. Plant antimicrobial agents and their effects on plant and human pathogens. Int. J. Mol. Sci. $10,3400-3419$.

Hamilton-Miller, J.M.T., Shah, S., 1999. Disorganization of cell division of methicillinresistant Staphylococcus aureus by a component of tea (Camellia sinensis): a study by electron microscopy. FEMS Microbiol. Lett. 176, 463-469.

Jorgensen, J.H., Turnidge, J.D., 2007. Susceptibility test methods: dilution and disk diffusion methods. In: Murray, P.R., Baron, E.J., Jorgensen, J.H., Landry, M.L., Pfaller, M.A. (Eds.), Manual of Clinical Microbiology, 9th ed. ASM Press, Washington D.C, pp. 1152-1172.

Karabacak, S., Bozkurt, H., 2008. Effects of Urtica dioica and Hibscus sabdariffa on the quality and safety of sucuk (Turkish dry-fermented sausage). Meat. Sci. 3, 288-296.

Kim, H.K., Thammavongsa, V., Schneewind, O., Missiakas, D., 2012. Recurrent infections and immune evasion strategies of Staphylococcus aureus. Curr. Opin. Microbiol. 15 (1), 92-99.

Kritsidima, M., Newton, T., Asimakopoulou, K., 2009. The effect of lavender scent on dental patient anxiety levels: a luster randomized-controlled trial. Community Dent. Oral Epidemiol. 38, 83-87.

Liu, R.H., 2003. Health benefits of fruit and vegetables are from additive and synergistic combinations of phytochemicals. Am. J. Clin. Nutr. 78, 517S-520S.

Lowy, F.D., 2003. Antimicrobial resistance: the example of Staphylococcus aureus. J. Clin. Invest. 111, 1265-1273.

Moon, T., Wilkinson, J.M., Cavanagh, H.M.A., 2006. Antibacterial activity of essential oils, hydrosols and plant extracts from Australian Grown Lavandula spp. Int. J. Aromather. 16, 9-14.

Motamedi, H., Seyyednejad, S.M., Bakhtiari, A., Vafaei, M., 2014. Introducing urtica dioica, a native plant of khuzestan, as an antibacterial medicinal plant. Jundishapur J. Nat .Pharm. Prod. 9 (4), e15904.

Pinzur, M.S., Slovenkai, M.P., Trepman, E., Shields, N.N., 2005. Guidelines for diabetic foot care: recommendations endorsed by the Diabetes Committee of the American Orthopaedic Foot and Ankle Society. Foot Ankle Int. 26, 113-119.

Reveles, K.R., Duhon, B.M., Moore, R.J., Hand, E.O., Howell, C.K., 2016. Epidemiology of methicillin-resistant Staphylococcus aureus diabetic foot infections in a large academic hospital: implications for antimicrobial stewardship. PLoS One 11 (8), e0161658.

Rodríguez-Vaquero, M.J., Alberto, M.R., Manca de Nadra, M.C., 2007. Antibacterial effect of phenolic compounds from different wines. Food Control 18, 93-101.
Saavedra, M.J., Borges, A., Dias, C., Aires, A., Bennett, R.N., Rosa, E.S., Simões, M., 2010. Antimicrobial Activity of Phenolics and Glucosinolate Hydrolysis products and their synergy with streptomycin against pathogenic bacteria. Med. Chem. 6, 174-183.

Sarker, S.D., Nahar, L., Kumarasamy, Y., 2007. Microtitre plate-based antibacterial assay incorporating resazurin as an indicator of cell growth, and its application in the in vitro antibacterial screening of phytochemicals. Methods 42, 321-324.

Sasaki, J., Yamanouchi, K., Nagaki, M., Arima, H., Aramachi, N., Inaba, T., 2015. Antibacterial effect of lavender (Lavandula) flavor (Volatile). J. Food Sci. Eng. 5, 95-102.

Sebranek, J.G., Sewalt, V.J.H., Robbins, K.L., House, T.A., 2005. Comparison of a natural rosemary extract and BHA/BHT for relative antioxidant effectiveness in pork sausage. Meat. Sci. 69, 289-296.

Shahin Gavanji, S., Mohammadi, E., Larki, B., Azizollah Bakhtari, A., 2014. Antimicrobial and cytotoxic evaluation of some herbal essential oils in comparison with common antibiotics in bioassay condition. Integr. Med. Res. 3 (3), 142-152.

Shin, Y., Ryu, J.A., Liu, R.H., Nock, J.F., Polar-Cabrera, K., Watkins, C.B., 2008. Fruit quality, antioxidant contents and activity, and antiproliferative activity of strawberry fruit stored in elevated $\mathrm{CO}_{2}$ atmospheres. J. Food Sci. 73, S339-S344.

Shintani, H.T., Aga, Y., Shiota, S., Tsuchiya, T., Yoshida, T., 2000. Phenolic constituents of licorice VII Structures of glicophenone and glicoisoflavanone, and effects of licorice phenolics on methicillin-resistant Staphylococcus aureus. Chem. Pharm. Bull. 48, 1286-1292.

Singh, N., Armstrong, D.G., Lipsky, B.A., 2005. Preventing foot ulcers in patients with diabetes. J. Am. Med. Assoc. 293, 217-228.

Singleton, V.L., Orthofer, R., Lamuela-Raventos, R.M., 2002. Analysis of total phenol and other oxidative substrates and antioxidants by means of Folin-ciocalteu reagent. Methods Enzymol. 299, 152-178.

Sung, W.S., Lee, D.G., 2010. Antifungal action of chlorogenic acid against pathogenic fungi, mediated by membrane disruption. Pure Appl. Chem. 82, 219-226.

Tahri, A., Yamani, S., Legssyer, A., Aziz, M., Mekhfi, H., Bnouham, M., Ziyyat, A., 2000. Acute diuretic, natriuretic and hypotensive effects of a conyinuous perfusion of aqueous extract of Urtica dioica in the rat. J. Ethnopharmacol. 73, 95-100.

Wilke, M.S., Loverin, A.L., Strynadka, N.C.J., 2005. $\beta$-Lactam antibiotic resistance: a current structural perspective. Curr. Opin. Microbiol. 8, 525-533.

Woènicka, E., Kuèniari, A., Nowak, D., Nykieli, E., Kopacz, M., Gruszecka, J., Golec, K., 2013. Antibacterial activity of some flavonoids and their sulfonic derivatives. Acta Pol. Pharm. 70, 567-571.

WHO (World Health Organization), 2017. Global Priority List of Antibiotic-resistant Bacteria to Guide Research, Discovery, and Development of New Antibiotics. World Health Organization.

Zhang, Y., Li, X., Wang, Z., 2010. Antioxidant activities of leaf extract of Salvia miltiorrhiza Bunge and related phenolic constituents. Food Chem. Toxicol. 48, 2656-2662. 